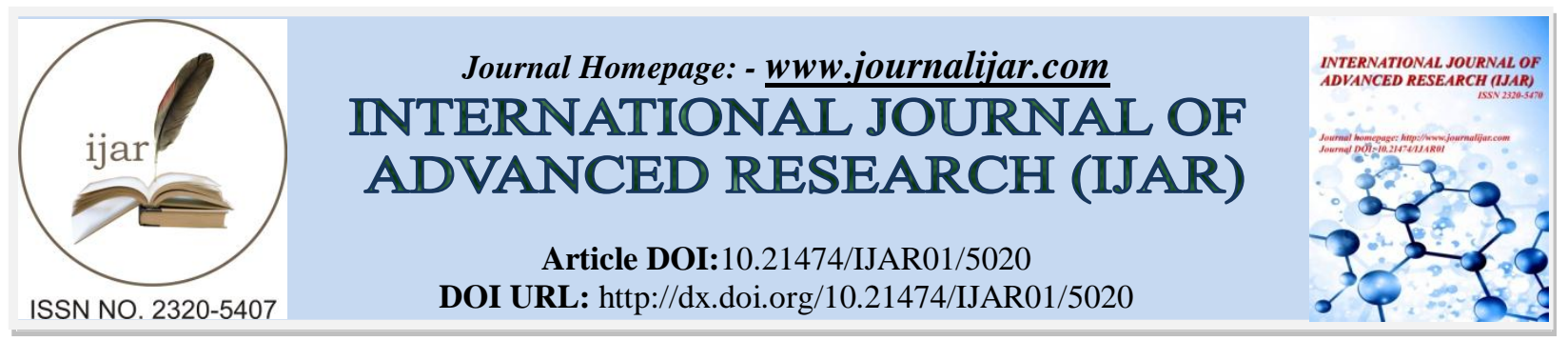

RESEARCH ARTICLE

\title{
THE PLEIOTROPIC EFFECTS OF CURCUMIN.
}

\section{Akila Srinivasan ${ }^{1}$, Sandhiya Selvarajan ${ }^{2}$ and Steven Aibor Dkhar ${ }^{3}$.}

1. Junior Resident, Department of Pharmacology, Jawaharlal Institute of Postgraduate Medical Education and Research(JIPMER), Puducherry, India.

2. Assistant Professor, Department of Clinical Pharmacology, Jawaharlal Institute of Postgraduate Medical Education and Research(JIPMER) ,Puducherry, India.

3. Professor(Senior Scale) and Head, Department of Clinical Pharmacology, Jawaharlal Institute of Postgraduate Medical Education and Research(JIPMER) ,Puducherry, India.

\section{Manuscript Info}

Manuscript History

Received: 28 May 2017

Final Accepted: 30 June 2017

Published: July 2017

\section{Abstract}

Recently, many natural substances have been increasingly found to have significant biological properties which make them useful in the treatment of various diseases. Nature has plenty of healing properties which makes it invaluable for its role towards promotion of a healthy world.

Turmeric (Curcuma longa), one of the frequently used spices in Indian cooking, is renowned for its medicinal properties from time immemorial. It is well known to possess anti inflammatory, anti oxidant, antiseptic and anti cancer properties with an excellent safety profile. The active principles of this spice are curcumin, demethoxycurcumin and bisdemethoxycurcumin. From preclinical studies to clinical trials, tremendous progress has been made with respect to this compound in the medical field .This review will focus on the effects of curcumin and its mechanisms of action in various disease conditions.

Copy Right, IJAR, 2017,. All rights reserved.

\section{Introduction:-}

Turmeric(Curcuma longa) is a rhizomatous plant of the Zingiberaceae family and one of the widely used spices in Indian cooking. The chemical structure of curcumin, the most active constituent was identified as diferuloylmethane in 1910 by Milobedzka and Lampe ${ }^{[1]}$.Later Srinivasan separated the 3 curcuminoids by Chromatography as curcumin (diferuloylmethane) ,p-hydroxycinnamoylferuloylmethane and p,p' -dihydroxydicinnamoylmethane ${ }^{[2]}$. These 3 curcuminoids are commonly referred as curcumin(diferuloylmethane), demethoxycurcumin and bisdemethoxycurcumin and volatile oils such astumerone, atlantone, and zingiberone in addition to sugars, proteins and resins ${ }^{[3]}$.

Curcumin is the chief constituent of turmeric, which is a spice used traditionally in Indian medicine for its role in diabetes and associated conditions ${ }^{[4]}$.It is also known to have anti-cancer, antioxidant, anti-inflammatory and antiseptic properties ${ }^{[5]}$.In this review article, the various roles of curcumin in medicine will be discussed

Corresponding Author:-Akila Srinivasan.

Address:- Junior Resident, Department of Pharmacology, Jawaharlal Institute of Postgraduate Medical Education and Research (JIPMER), Puducherry, India. 


\section{As an anti-cancer agent:-}

Curcumin exerts anti-cancer activity through multiple molecular mechanisms. Curcumin inhibits tumorigenesis by inhibiting action of the transcription factor $N F-\kappa B$, which is stimulated by various factors like oxidative stress and pro-inflammatory cytokines like TNF- $\alpha$ and IL- ${ }^{[5]}$. Curcumin was first shown to inhibit NF- $\kappa$ B by Singh and Aggarwal in $1995^{[6]}$.AP-1 is another transcription factor which is stimulated by the above factors as well as by radiation ${ }^{[5]}$.Both these transcription factors are key regulators of cell cycle, leading to uncontrolled cellular proliferation ${ }^{[5]}$.It has been seen that in pancreatic cancer $\mathrm{NF}-\kappa \mathrm{B}$ is over active and by inhibiting this, curcumin at a dose of 8g/day produced reduction in cytokine(IL-6,8,10) and CA-125 levels in a patient of pancreatic cancer and improved this patient's condition over 1 year ${ }^{[7]}$.In a study to determine the antiproliferative effect of curcumin on colon cancer( DLD-1)cell lines, it was found that curcumin induced apoptosis in these cells which was 3 fold more than produced by control and its combination with silymarin exhibited 5 times more apoptosis as compared to control, which indicates that curcumin sensitizes apoptotic action of silymarin since activity of NF-kB is inhibited by both these compounds ${ }^{[8]}$.

A study done on A549 cells, which is a lung adenocarcinoma cell line, showed that curcumin could be a supportive treatment for lung cancer in the coming years as it can suppress the movement and invasive ability of A549 cells by hindering adiponectin expression, which is responsible for stimulation of AKT pathway, which is in turn related to stimulation of the NF- $\kappa$ B pathway ${ }^{[9]}$

An in vitro study was done on glioma GBM 8401 cells, which are malignant glioma cells of the human brain ,where these cells were treated with demethoxycurcumin(DMC) at rising doses of $0,12.5,25,50$, and $100 \mu \mathrm{M}$ for 1 or 2 days ${ }^{[10]}$ DMC was shown to reduce multiplication of these cells and decrease their survival and lead to apoptosis by induction of caspase activity ${ }^{[10]}$.In a similar study, the in vitro effect of curcumin was studied on multiple human glioblastoma cell lines, both primary and recurrent, where it was found to exhibit a dose dependent decline in proliferation of these cells, which could be explained by hampering the STAT- 3 pathway of signalling ${ }^{[11]}$.

In a study done on HMCL (Human Myeloma cell lines), it was shown that Mcl-1, which is an important protein for myeloma cells to survive in the body, was drastically downregulated in curcumin treated cells ${ }^{[12]}$.Some subgroups of myeloma cell lines like $\mathrm{t}(4 ; 14)$ and $\mathrm{t}(14 ; 16)$, which are usually considered as poor prognostic factors were found to be highly sensitive to curcumin ${ }^{[12]}$.

Curcumin was found to sensitize HeLa cancer cell lines to radiation in an in vitro study by increasing reactive oxygen species thereby causing extracellular signal-regulated kinase (ERK) $1 / 2$ activation ${ }^{[13]}$.In a randomized, double-blind, placebo-controlled trial to study the effects of oral curcumin( dose of 6 grams daily) in lessening the effect of radiation dermatitis in patients with breast cancer, curcumin was found to produce a statistically significant decrease in the Radiation Dermatitis Severity (RDS) score and moist desquamation ${ }^{[14]}$.

In a study done on Rh30 and Rh41 cells, which are human rhabdomyosarcoma cell lines of the alveolar subtype, curcumin, by suppressing NF-kB activity (a transcription factor whose activity is stimulated by ionizing radiation) was found to have a radiosensitizing action ${ }^{[15]}$. NF-kB activity increased by radiation is responsible for radioresistance in these ARMS cells( Alveolar Rhabdomyosarcoma) ${ }^{[15]}$.

In another study done on ovarian cancer cells which were resistant to cisplatin, pretreatment with curcumin produced higher inhibition of cancer cell proliferation than either curcumin or cisplatin given alone and also produced an appreciable decline in the required cisplatin dose, demonstrating its chemosensitising action ${ }^{[16]}$. In the same experiment these curcumin pretreated cells exposed to radiation exhibited more suppression of colony formation than either agent (curcumin or radiation) alone ${ }^{[16]}$.

\section{In diabetes/Metabolic syndrome:-}

In mice models fed with high fat diet (HFD), curcumin has been found to reduce action of this diet on weight gain and improved insulin sensitivity ${ }^{[17]}$. Rise in levels of fasting plasma insulin induced by HFD was found to be decreased by curcumin. ${ }^{[17]}$

Similarly a randomized control trial was conducted on subjects with metabolic syndrome who had a weight loss of $<2 \%$ even after lifestyle modification and change in diet given for a period of 30 days and the subjects had a mean weight loss of around $1.88 \%$, a BMI reduction of $2.10 \%$, a reduction in percentage fat of $0.70 \%$. ${ }^{[18]}$ In this trial for 
the next 30 days the study group received Curcuma longa extract $800 \mathrm{mg} / \mathrm{dose} / \mathrm{die}$ (95\% curcumin) with phosphotidylserine which is mixed with piperine $8 \mathrm{mg} / \mathrm{dose} / \mathrm{die}$ and the control group received phosphotidylserine 400mg/dose/die. ${ }^{[18]}$ The study group had significant decrease in anthropometric measurements like weight loss of around $4.91 \%$ (from $1.88 \%$ ), BMI reduction of $6.43 \%$ ( from previous $2.10 \%$ ), and body fat decreased from previous $0.70 \%$ to $8.43 \%$. There was no effect in the phosphotidylserine group. Also both groups had good compliance with similar tolerability with 2 patients of the control group having gastric burning as a side effect. ${ }^{[18]}$

Curcumin reduces insulin resistance and increases the levels of anti inflammatory cytokines like adiponectin ${ }^{[19]}$ Curcumin was also found to significantly reduce inflammation in adipose tissue by increasing adiponectin expression and bringing down the expression of F4/80, which is a marker of murine macrophages in white adipose tissue. ${ }^{[20]}$

In a study done on patients with type 2 diabetes mellitus, the effect of NCB-02( a standardized curcuminoid preparation), atorvastatin and placebo was studied on endothelial function and various biomarkers like malondialdehyde, endothelin-1 (ET-1), interleukin-6 (IL-6) and tumour necrosis factor- $\alpha$ (TNF $\alpha$ ) at baseline and after weeks. Endothelial function improved significantly in both NCB-02 and atorvastatin groups from baseline values of reflective index ${ }^{[21]}$. The levels of the above biomarkers were also decreased significantly in both the groups as compared to placebo. The above results show that NCB-02 has a similar effect, like that of atorvastatin in improving endothelial dysfunction and decreasing inflammatory cytokines and oxidative stress markers. ${ }^{\text {[21] }}$

In a randomized controlled trial done on patients of Acute Coronary Syndrome, double blinding was done to study the effects of low dose, moderate dose and high dose curcumin and placebo on lipid profile. ${ }^{[22]}$ The low dose group receiving $15 \mathrm{mg}$ thrice a day and the moderate dose group receiving $30 \mathrm{mg}$ thrice a day were found to have decrease in total cholesterol and LDL cholesterol level, but it was not statistically significant when compared to placebo. ${ }^{[22]}$

\section{In skin diseases:-}

In a randomized, double blind, placebo controlled trial conducted on patients with psoriasis, patients were assigned $1: 1$ to 2 groups with test group receiving methylprednisolone aceponate $0.1 \%$ Ointment and 2 gms/day Curcumin (Meriva, which is curcumin delivered in a lecithin base) and control group receiving methylprednisolone aceponate $0.1 \%$ ointment plus matching placebo. ${ }^{[23]}$ Decrease in disease severity was evaluated by PASI (Psoriasis Area Severity Index) measured after 12 and 16 weeks. ${ }^{[23]}$ The levels of cytokine IL-17 and IL-22 was analysed at baseline and 12 weeks. Though decrease in PASI values was significant in both the test and control groups at 16 weeks( $p<0.05$ for both groups), the group treated with curcumin(topical steroid and Meriva) had more decrease in PASI values than the control group(topical steroid and placebo) ${ }^{[23]}$. Though there was no change in levels of IL-17 in both the groups at baseline and week 12, the levels of IL-22 showed a significant decrease at week 12 in the curcumin and topical steroid group, whereas there was no change in the topical steroid and placebo group at week $12^{[23]}$

Levels of IL-22 were found to be significantly higher in patients with psoriasis ${ }^{[24]}$ and may be responsible for increasing the thickness of epidermis probably by interfering with differentiation of terminal keratinocyte ${ }^{\text {[25] }}$

\section{In the treatment of osteoarthritis:-}

In a randomized, double blind, multicenter study to assess efficacy of Curcuma domestica $1500 \mathrm{mg} / \mathrm{day}$ (containing $75 \%$ to $85 \%$ curcuminoids) over ibuprofen $1200 \mathrm{mg} /$ day usingWestern Ontario and McMaster Universities Osteoarthritis Index (WOMAC), C.domestica group was found to be non inferior to ibuprofen group in terms of reduction in WOMAC pain and function scores ${ }^{[26]} \mathrm{A}$ greater WOMAC score is associated with more pain and limitation of functions ${ }^{[27]}$

In an observational study done in patients with osteoarthritis of the knee the effect of Meriva®) (which is a new formulation of curcumin in lecithin delivery system) along with glucosamine was compared with another group which received chondroitin sulphate and glucosamine ${ }^{[28]}$. The functional status of the knee was assessed using The Karnofsky Performance Scale Index and WOMAC questionnaire was used to report their signs and symptoms of $\mathrm{OA}$ at baseline and after the study period ${ }^{[28]}$ A lesser Karnofsky Index indicates a worse functional status ${ }^{[29] .}$ The Meriva and glucosamine group had significantly greater Karnofsky Index and significant reduction in WOMAC pain, stiffness and function score ${ }^{[28]}$. 
The addition of curcumin was found to enhance the effect of celecoxib by suppressing COX-2 activity and stimulating apoptosis in osteoarthritis synovial adherent cells( fibroblast like cells). ${ }^{[30]}$ Fibroblasts in synovium secrete increased amounts of IL- 6 and finite amounts of TNF- $\alpha$ which may be lead to their arthritogenic action. ${ }^{[31]}$

\section{Curcumin in neuroprotection:-}

A study was done to demonstrate the neuroprotective effects of curcumin and cur1, a derivative of curcumin in Alzheimers disease, using an in vitro model of SK-N-SH cells, which is a human cell line derived from neuroblastoma ${ }^{[32]}$ Curcumin and cur1 were found to guard these cells from action of externally added amyloidbeta1-42 by stimulating the activity of telomerase ${ }^{[32]}$ In another study done on japanese encephalitis infected Neuro2a cell line,the neuroprotective role of curcumin was studied. Japanese Encephalitis Virus(JEV) Infection was found to cause an incline in the levels of reactive oxygen radicals and stress kinase pathways like pJNK, phosphop38 MAPK, phosphoERK-1,2, and pNFк $\beta$ whcih were found to be significantly reduced in cells treated with curcumin as compared to control ${ }^{[33]}$.Curcumin also suppressed ubiquitin-proteasome system and thereby decreased formation of infective viral particles from N2a cells which were previously infected ${ }^{[33]}$.p38MAPK and pJNK are important signaling molecules which are linked to cell death mediated by TNFR-1( Tumar Necrosis Factor Receptor-1) seen in JEV-infected N2a cell lines ${ }^{[34]}$.

In a model of Parkinson's disease on SH-SY5Y cells, incubation of cells with oligomeric $\alpha$-synuclein $(\alpha \mathrm{S})$ lead to cytotoxicity, increased the ROS( Reactive Oxygen Species) level, and induced apoptosis by stimulating Caspase-3 pathway, all of which were diminished by curcumin ${ }^{[35]}$.

\section{Curcumin in Gastrointestinal disorders:-}

The role of curcumin on gastrointestinal disorders has been extensively investigated and found to be effective in experimental models and its role clinically has been demonstrated in some clinical trials.

In a randomized, double blind pilot study done in patients of ulcerative colitis, the subjects were randomized into two groups consisting of NCB-02 ( which is a standardized curcumin preparation) enema along with oral 5-ASA or a control group of placebo enema with oral 5-ASA ${ }^{[36]}$ Patients were evaluated using UCDAI scoring( Ulcerative Colitis Disease Activity Index) . Though the intention to treat analysis showed that treatment response was better and number of patients who had remission and had better mucosal healing were more in NCB -02 group, it was not statistically significant. But in per protocol analysis the above parameters(treatment response, remission and mucosal healing) were found to be statistically significant in NCB-02 group as compared to the control group ${ }^{[36]}$

In a randomized control trial done to study the effectiveness of curcumin on RAS (Recurrent Aphthous Stomatitis), curcumin gel was compared with triamcinolone acetonide gel and both the groups were compared with regard to reduction in the pain, number and size of the ulcers ${ }^{[37]}$ Though both the groups showed statistically significant reduction in pain, size and number of ulcers from day 0 to day 7 , there was no statistical significance in the above parameters between the two groups( curcumin and triamcinolone acetonide), showing that curcumin gel is a convincing alternative to corticosteroids in the management of RAS $^{[37]}$

An important mechanism of anti inflammatory property of curcumin is reducing levels of proinflammatory cytokines which could be through suppression of NF- $\mathrm{kB} .{ }^{[38]}$ Higher levels of NF- $\mathrm{KB}$ is seen in intestinal biopsies taken from lamina propria of IBD patients. ${ }^{[39]}$ The activation of the transcription factor NF- $\mathrm{KB}$ leads to upregulation of various inflammatory cytokines like IL-6, IL-8, and TNF-a in a study done on human gestational tissues from women who underwent elective caesarean section and delivered healthy full term infants ${ }^{[40]}$

\section{The anti-infective role of curcumin:-}

In a study done on human genital epithelial cells (GECs) taken from hysterectomised specimens, 5 or $50 \mu \mathrm{M}$ curcumin was added to GECs 1 hour before exposure to HIV and HSV infected cell lines, which is a concentration of curcumin enough to inhibit TNF- $\alpha$ stimulation ${ }^{[41]}$ In a previous study it was shown that gp 120 induced activation of pro inflammatory cytokines like TNF- $\alpha$ leads to suppression of TJ (Tight Junction) proteins, like ZO-1 and occludin which are usually expressed in GECs, thereby leading to mucosal barrier damage ${ }^{[42,43]}$. Such mucosal barrier damage can be avoided by pre treatment of GECs by curcumin, which preserves the expression of TJ proteins ${ }^{[41]}$.Curcuminpre treated human GECs also had significant suppression of HSV-2 multiplication ${ }^{[41]}$. 


\section{Curcumin and cardiovascular system:-}

In a study done on human ventricular cardiomyocytes (HVCM), nanocurcumin at a dose of $500 \mathrm{ng} / \mathrm{ml}$ was shown to have cardioprotective action ${ }^{[44]}$. Cardiac hypertrophy promoted by hypoxia in these cells showed a decline in nanocurcumin treated cardiomyocytes and these cells were found to be more viable ${ }^{[44]}$.Also shift of energy source of cardiomyocytes from lipids to glucose under hypoxic conditions was hampered by nanocurcumin and mitochondrial function was conserved by nanocurcumin in hypoxic conditions ${ }^{[44]}$.

An in vitro study done on MCF-7 breast cancer cells some of which were partially doxorubicin resistant, HO-3867 ( which is a synthetic curcumin compound), was used in combination with doxorubicin to see the anti cancer effect of the combination as well as to see the cardioprotective action of HO-3867 on normal cardiac cells and endothelial cells of the aorta which were used as controls ${ }^{[45]}$. It was seen that that the cytotoxic activity of the combination was better than either doxorubicin or HO-3867 on its own. But the cytotoxicity of doxorubicin on the normal cells ( used as control ) was diminished by the addition of HO-3867 to doxorubicin ${ }^{[45]}$.

\section{Curcumin in Asthma:-}

In an open label study conducted to see the effect of curcumin in asthmatic patients as an add on therapy, patients were randomized into two groups, A (Standard therapy consisting of budesonide, formoterol along with montelukast, levocetrizine and acebrophylline) and B( above mentioned Standard therapy and curcumin $500 \mathrm{mg}$ bd for 1 month). There was found to be significant betterment in the $\mathrm{FEV}_{1}$ values in the curcumin group and betterment of various hematological parameters like total leukocyte count(TLC). ${ }^{[4]}$ Regarding the adverse effects, though both study groups reported headache and insomnia, weight gain was recorded in group B alone and decrease in appetite only in group A patients and there were no significant adverse effects clinically, suggesting the clinical efficacy and safety of curcumin as add on therapy in bronchial asthma ${ }^{[46]}$ Curcumin has been shown to suppress cPLA2 (cytosolic phospholipase A2)phosphorylation and thereby reduce arachidonic acid release and also hinder the catalytic action of 5-LOX(5-Lipoxygenase) and hamper COX-2 expression induced by LPS ${ }^{[47]}$

\section{Curcumin in Uveitis:-}

In a study done to study the efficacy of phospholipidic curcumin on anterior uveitis of various underlying causes, patients were given oral Norflo tablets (which is curcumin-phosphatidylcholine complex; Meriva $\left.{ }^{\circledR}\right)$ ) twice a day. The patients were assessed before and after therapy by assessing the frequency of relapses in each patient. The results showed that 106 and 19 patients had relapses before and after therapy by Norflo. ${ }^{[4]}$ Since some patients had more than 1 relapse of anterior uveitis, by adding the total number of relapses of all patients, there were 275 and 36 relapses before and after treatment, which is remarkably significant with a p value less than 0.001 . Symptoms of ocular discomfort were also decreased after a few weeks in patients treated with Norflo. ${ }^{[48]}$ This could be explained by the anti inflammatory action of curcumin, which is a PPAR- $\gamma$ agonist. ${ }^{[49]}$ Many ocular inflammatory diseases are mediated by immune cells such as microglia and the anti inflammatory action of PPAR- $\gamma$ may be effective in these conditions $^{[50]}$.

\section{Curcumin on depression:-}

The effect of curcumin has also been evaluated in depressive disoders. In a study done patients of major depressive disorder(MDD), Curcumin was found to have efficacy comparable to fluoxetine ${ }^{[51]}$ But this study was not placebo controlled and had a less number of study participants ${ }^{[51]}$

In a Randomised control trial done on patients of major depressive disorder, double blinding was done and the patients were randomized into curcumin $\left(500 \mathrm{mg}\right.$ bd) or placebo group. ${ }^{[52]}$ The study was carried out for 8 weeks. Betterment in the Inventory of Depressive Symptomatology self-rated version (IDS-SR30) was employed as the primary outcome. ${ }^{[52]}$ The secondary outcomes used to assess effect of curcumin were IDS-SR30 factor scores and the Speilberger State-Trait Anxiety Inventory (STAI).Though there was no significant difference between the two groups in the first four weeks in decreasing depressive and anxiety symptoms, from week 4 to 8 , the curcumin group was more efficacious than placebo in bringing down both depressive and anxiety symptoms as shown by improvement in IDS-SR30 total score and IDS-SR30 mood score ${ }^{[52]}$

Curcuma longa was found to inhibit MAO A in mouse brain, which is responsible for its antidepressant effects ${ }^{[53]}$ Curcumin which inhibits MAO plays an important role in the metabolism of various monoamines like dopamine, noradrenaline and 5-hydroxytryptamine. ${ }^{[33]}$ Curcumin was found to exert its antidepressant effects in mice by interacting with serotonergic receptors 5-HT1 and 5-HT2. ${ }^{[54]}$ 
The pleiotropic effects of curcumin can be summarised in the following table(table no. 1):

Table no.1:-Mechanism of action of curcumin in various conditions.

\begin{tabular}{|c|c|}
\hline Property & $\begin{array}{l}\text { Mechanism of Action (Numbers in brackets indicates reference number of the study } \\
\text { quoted in text) }\end{array}$ \\
\hline Anti cancer & $\begin{array}{l}\text { inhibiting action of NF- } \kappa B^{[6]} \\
\text { apoptosis by induction of caspase activity (demethoxycurcumin) })^{[10]} \\
\text { Mcl-1 downregulation }{ }^{[12]} \\
\text { Radiosensitisation }^{[15]} \\
\text { Chemosensitisation }^{[16]}\end{array}$ \\
\hline $\begin{array}{l}\text { Diabetes/metabolic } \\
\text { syndrome }\end{array}$ & $\begin{array}{l}\text { Improve insulin sensitivity }{ }^{[17]} \\
\text { increases the levels of anti inflammatory cytokines like adiponectin }{ }^{[19,20]} \\
\text { improved endothelial function } \\
\text { decrease in inflammatory cytokines and oxidative stress markers }^{[21]}\end{array}$ \\
\hline Skin diseases & decreases IL-22 levels $^{[23]}$ \\
\hline $\begin{array}{l}\text { Osteoarthritis } \\
\text { (Curcuma domestica) }\end{array}$ & apoptosis of synovial adherent cells. ${ }^{[30]}$ \\
\hline $\begin{array}{l}\text { Neuroprotection } \\
\text { Alzheimer disease(in } \\
\text { vitro) }\end{array}$ & protected cells from amyloid-beta1-42 action by stimulating activity of telomerase ${ }^{[32]}$ \\
\hline $\begin{array}{l}\text { Japanese Encephalitis } \\
\text { cell lines }\end{array}$ & $\begin{array}{l}\text { Reduction in reactive oxygen radicals and stress kinase pathways }{ }^{[33]} \\
\text { suppressed ubiquitin-proteasome system } \\
{[33]}\end{array}$ \\
\hline Anti infective Role & preserves the expression of TJ proteins $^{[41]}$ \\
\hline $\begin{array}{ll}\text { Gastro intestinal } \\
\text { disorders }\end{array}$ & $\begin{array}{l}\text { anti inflammatory property -decreasing pro inflammatory cytokines by suppression of } \\
\mathrm{NF}-\kappa \mathrm{B} \cdot{ }^{[38]}(\mathrm{NF}-\kappa \mathrm{B} \text { is raised in intestinal biopsies of IBD patients })^{[39]}\end{array}$ \\
\hline $\begin{array}{l}\text { Cardiovascular } \\
\text { system(Nanocurcumin) }\end{array}$ & conserves mitochondrial function, under hypoxic conditions ${ }^{[44]}$ \\
\hline Bronchial asthma & $\begin{array}{l}\begin{array}{l}\text { Reduce arachidonic acid release by suppressing cytosolic phospholipase A2 } \\
\text { phosphorylation }{ }^{[47]}\end{array} \\
\end{array}$ \\
\hline uveitis & $\begin{array}{l}\text { anti inflammatory action of curcumin } \\
\text { PPAR- } \gamma \text { agonistic action- anti inflammatory property. }{ }^{[49,50]}\end{array}$ \\
\hline depression & $\begin{array}{l}\text { inhibit MAO A in mouse brain } \\
\text { interacting with serotonergic receptors } \\
\end{array}$ \\
\hline
\end{tabular}

\section{References:-}

1. Milobedzka J, Kostanecki S, Lampe V. ZurKenntnis des Curcumins. Ber. Deut. Chem. Ges.1910;43:2163-70

2. Srinivasan KR. A chromatographic study of the curcuminoids in Curcuma longa, L. J Pharm Pharmacol.1953;5:44857.

3. Jurenka JS. Anti-inflammatory properties of curcumin, a major constituent of Curcuma longa: a review of preclinical and clinical research.Altern Med Rev 2009 ;14:141-53

4. Jiménez-Osorio AS, Monroy A, Alavez S. Curcumin and insulin resistance-Molecular targets and clinical evidences. BioFactors. 2016 Jun 21.

5. Wilken R, Veena MS, Wang MB, Srivatsan ES. Curcumin: A review of anti-cancer properties and therapeutic activity in head and neck squamous cell carcinoma. Molecular cancer. $2011 ; 10: 12$

6. Singh S, Aggarwal BB. Activation of transcription factor NF-kappa B is suppressed by curcumin (diferuloylmethane). J Biol Chem. 1995 Oct ;270:24995-5000.

7. Dhillon N, Aggarwal BB, Newman RA, Wolff RA, Kunnumakkara AB, Abbruzzese JL, et al. Phase II trial of curcumin in patients with advanced pancreatic cancer. Clinical Cancer Research. 2008 ;14:4491-9.

8. Montgomery A, Adeyeni T, San K, Heuertz RM, Ezekiel UR. Curcumin Sensitizes Silymarin to Exert Synergistic Anticancer Activity in Colon Cancer Cells.J Cancer. 2016 ;7:1250-7

9. Tsai J-R, Liu P-L, Chen Y-H, Chou S-H, Cheng Y-J, Hwang J-J, et al. CurcuminInhibitsNon-Small Cell Lung Cancer Cells Metastasis through the Adiponectin/NF-kb/MMPs Signaling Pathway. PLoS One 2015;10:e0144462. 
10. Huang TY, Hsu CW, Chang WC, Wang MY, Wu JF, Hsu YC. Demethoxycurcumin retards cell growth and induces apoptosis in human brain malignant glioma GBM 8401 cells. Evid Based Complement Alternat Med. 2012 Feb $15 ; 2012$.

11. Senft C, Polacin M, Priester M, Seifert V, Kögel D, Weissenberger J. The nontoxic natural compound Curcumin exerts anti-proliferative, anti-migratory, and anti-invasive properties against malignant gliomas. BMC Cancer. 2010;10:491.

12. Gomez-Bougie P, Halliez M, Maïga S, Godon C, Kervoëlen C, Pellat-DeceunynckC,et al. Curcumin induces cell death of the main molecular myeloma subtypes, particularly the poor prognosis subgroups. Cancer BiolTher. 2015 ;16:60-5.

13. Javvadi P, Segan AT, Tuttle SW, Koumenis C. The chemopreventive agent curcumin is a potent radiosensitizer of human cervical tumor cells via increased reactive oxygen species production and overactivation of the mitogenactivated protein kinase pathway. MolPharmacol. 2008;73:1491-501.

14. Ryan JL, Heckler CE, Ling M, Katz A, Williams JP, Pentland AP, et al. Curcumin for radiation dermatitis: a randomized, double-blind, placebo-controlled clinical trial of thirty breast cancer patients. Radiat Res. 2013;180:3443.

15. Orr WS, Denbo JW, Saab KR, Ng CY, Wu J, Li K, et al. Curcumin potentiates rhabdomyosarcoma radiosensitivity by suppressing NF- $\kappa$ B activity. PLoS One. 2013;8:e51309.

16. Yallapu MM, Maher DM, Sundram V, Bell MC, Jaggi M, Chauhan SC. Curcumin induces chemo/radio-sensitization in ovarian cancer cells and curcumin nanoparticles inhibit ovarian cancer cell growth. J Ovarian Res. 2010 ;3:11.

17. Shao W, Yu Z, Chiang Y, Yang Y, Chai T, Foltz W, et al. Curcumin prevents high fat diet induced insulin resistance and obesity via attenuating lipogenesis in liver and inflammatory pathway in adipocytes. PloS one. $2012 ; 7: \mathrm{e} 28784$.

18. Di Pierro F, Bressan A, Ranaldi D, Rapacioli G, Giacomelli L, Bertuccioli A. Potential role of bioavailable curcumin in weight loss and omental adipose tissue decrease: Preliminary data of a randomized, controlled trial in overweight people with metabolic syndrome. Preliminary study. Eur Rev Med Pharmacol Sci. 2015 ;19:4195-202.

19. Chuengsamarn S, Rattanamongkolgul S, Luechapudiporn R, Phisalaphong C, Jirawatnotai S. Curcumin extract for prevention of type 2 diabetes. Diabetes care. 2012;35:2121-7.

20. Weisberg SP, Leibel R, Tortoriello DV. Dietary curcumin significantly improves obesity-associated inflammation and diabetes in mouse models of diabesity. Endocrinology. 2008;149:3549-58.

21. Usharani P, Mateen AA, Naidu MUR, Raju YSN, Chandra N. Effect of NCB-02, atorvastatin and placebo on endothelial function, oxidative stress and inflammatory markers in patients with type 2 diabetes mellitus. Drugs in $\mathrm{R}$ \& D. $2008 ; 9: 243-50$.

22. Alwi I, Santoso T, Suyono S, Sutrisna B, Suyatna FD, Kresno SB, et al. The effect of curcumin on lipid level in patients with acute coronary syndrome.Acta Med Indones. 2008 ;40:201-10.

23. Antiga E, Bonciolini V, Volpi W, Del Bianco E, Caproni M. Oral Curcumin (Meriva) is effective as an adjuvant treatment and is able to reduce IL-22 serum levels in patients with psoriasis vulgaris. BioMed research international. 2015 May 18;2015.

24. Michalak-Stoma A, Bartosińska J, Kowal M, Juszkiewicz-Borowiec M, Gerkowicz A, Chodorowska G. Serum levels of selected Th17 and Th22 cytokines in psoriatic patients. Dis Markers. 2013;35:625-31.

25. Boniface K, Bernard FX, Garcia M, Gurney AL, Lecron JC, Morel F. IL-22 inhibits epidermal differentiation and induces proinflammatory gene expression and migration of human keratinocytes. J Immunol. 2005;174:3695-702.

26. Kuptniratsaikul V, Dajpratham P, Taechaarpornkul W, Buntragulpoontawee M, Lukkanapichonchut P, ChootipC,et al. Efficacy and safety of Curcuma domestica extracts compared with ibuprofen in patients with knee osteoarthritis: a multicenter study.Clin Interv Aging. 2014;9:451-8.

27. http://www.rheumatology.org/I-Am-A/Rheumatologist/Research/Clinician-Researchers/Western-Ontario-McMasterUniversities-Osteoarthritis-Index-WOMAC, last accessed on 2016 august 22

28. Belcaro G, Dugall M, Luzzi R, Ledda A, Pellegrini L, Cesarone MR, et al. Meriva ${ }^{\circledR}+$ Glucosamine versus Condroitin+ Glucosamine in patients with knee osteoarthritis: an observational study. Eur Rev Med Pharmacol Sci. 2014;18:3959-63.

29. Schag CC, Heinrich RL, Ganz PA. Karnofsky performance status revisited: reliability, validity, and guidelines. J ClinOncol. 1984;2:187-93.

30. Lev-Ari S, Strier L, Kazanov D, Elkayam O, Lichtenberg D, Caspi D, et al. Curcumin synergistically potentiates the growth-inhibitory and pro-apoptotic effects of celecoxib in osteoarthritis synovial adherent cells. Rheumatology(Oxford). 2006;45:171-7.

31. Hirth A, Skapenko A, Kinne RW, Emmrich F, Schulze-Koops H, Sack U. Cytokine mRNA and protein expression in primary-culture and repeated-passage synovial fibroblasts from patients with rheumatoid arthritis. Arthritis Res. 2002;4:117-25.

32. Xiao Z, Zhang A, Lin J, Zheng Z, Shi X, Di W, et al.Telomerase: a target for therapeutic effects of curcumin and a curcumin derivative in A $\beta 1-42$ insult in vitro.PLoS One. 2014;9:e101251. 
33. Dutta K, Ghosh D, BasuA.Curcumin protects neuronal cells from Japanese encephalitis virus-mediated cell death and also inhibits infective viral particle formation by dysregulation of ubiquitin-proteasome system.JNeuroimmunePharmacol. 2009;4:328-37

34. Swarup V, Das S, Ghosh S, BasuA.Tumor necrosis factor receptor-1-induced neuronal death by TRADD contributes to the pathogenesis of Japanese encephalitis.JNeurochem. 2007;103:771-83

35. Wang MS, Boddapati S, Emadi S, Sierks MR. Curcumin reduces $\alpha$-synuclein induced cytotoxicity in Parkinson's disease cell model. BMC Neurosci. $2010 ; 11: 57$.

36. Singla V, Mouli VP, Garg SK, Rai T, Choudhury BN, Verma P, et al. Induction with NCB-02 (curcumin) enema for mild-to-moderate distal ulcerative colitis - a randomized, placebo-controlled, pilot study.JCrohns Colitis. 2014 ;8:208-14.

37. Deshmukh RA, Bagewadi AS. Comparison of effectiveness of curcumin with triamcinolone acetonide in the gel form in treatment of minor recurrent aphthous stomatitis: A randomized clinical trial. Int J Pharm Investig. 2014;4:138.

38. Jagetia GC, Aggarwal BB. "Spicing up" of the immune system by curcumin. J ClinImmunol 2007;27:19-35.

39. Schreiber S, Nikolaus S, Hampe J. Activation of nuclear factor $\kappa B$ in inflammatory bowel disease. Gut. 1998;42:47784.

40. Lappas M, Permezel M, Georgiou HM, Rice GE. Nuclear factor kappa B regulation of proinflammatory cytokines in human gestational tissues in vitro. BiolReprod. $2002 ; 67: 668-73$.

41. Ferreira VH, Nazli A, Dizzell SE, Mueller K, Kaushic C. The anti-inflammatory activity of curcumin protects the genital mucosal epithelial barrier from disruption and blocks replication of HIV-1 and HSV-2. PloS One. 2015 ;10:e0124903.

42. Nazli A, Chan O, Dobson-Belaire WN, Ouellet M, Tremblay MJ, Gray-Owen SD, et al. Exposure to HIV-1 directly impairs mucosal epithelial barrier integrity allowing microbial translocation. PLoSPathog. 2010;6:e1000852

43. Nazli A, Kafka JK, Ferreira VH, Anipindi V, Mueller K, Osborne BJ, et al. HIV-1 gp120 induces TLR2- and TLR4mediated innate immune activation in human female genital epithelium. J Immunol. 2013;191:4246-58.

44. Nehra S, Bhardwaj V, Ganju L, Saraswat D. Nanocurcumin Prevents Hypoxia Induced Stress in Primary Human Ventricular Cardiomyocytes by Maintaining Mitochondrial Homeostasis. PloS One.2015 ; 10:e0139121.

45. Dayton A, Selvendiran K, Meduru S, Khan M, Kuppusamy ML, Naidu S, et al. Amelioration of doxorubicin-induced cardiotoxicity by an anticancer-antioxidant dual-function compound, HO-3867. J PharmacolExpTher. 2011;339:3507

46. Abidi A, Gupta S, Agarwal M, Bhalla HL, Saluja M. Evaluation of Efficacy of Curcumin as an Add-on therapy in Patients of Bronchial Asthma. J ClinDiagn Res: 2014;8:HC19-HC24.

47. Hong J, Bose M, Ju J, Ryu JH, Chen X, Sang S, et al. Modulation of arachidonic acid metabolism by curcumin and related $\beta$-diketone derivatives: effects on cytosolic phospholipase A2, cyclooxygenases and 5-lipoxygenase. Carcinogenesis. 2004;25:1671-9.

48. Allegri P, Mastromarino A, Neri P. Management of chronic anterior uveitis relapses: efficacy of oral phospholipidic curcumin treatment. Long-term follow-up.Clin Ophthalmol. 2010;4:1201-6.

49. Jacob A, Wu R, Zhou M, Wang P. Mechanism of the anti-inflammatory effect of curcumin: PPAR- $\gamma$ activation. PPAR Res. 2007;2007:89369

50. Bernardo A, Minghetti L. Regulation of Glial Cell Functions by PPAR- $\boldsymbol{\gamma}$ Natural and Synthetic Agonists. PPAR Res. 2008;2008:864140

51. Sanmukhani J, Satodia V, Trivedi J, Patel T, Tiwari D, Panchal B, et al. Efficacy and safety of curcumin in major depressive disorder: a randomized controlled trial. Phytother Res. 2014;28:579-85.

52. Lopresti AL, Maes M, Maker GL, Hood SD, Drummond PD. Curcumin for the treatment of major depression: a randomised, double-blind, placebo controlled study. J Affect Disord. 2014 ;167:368-75.

53. Yu ZF, Kong LD, Chen Y. 2002. Antidepressant activity of aqueous extracts of Curcuma longa in mice. J Ethnopharmacol 83: 161-165.

54. Wang R, Xu Y, Wu HL, Li YB, Li YH, Guo JB, et al. The antidepressant effects of curcumin in the forced swimming test involve 5-HT 1 and 5-HT 2 receptors. Eur J Pharmacol. 2008;578:43-50. 